\title{
Cervical Osteoblastoma: Case Report
}

\section{S.H TOUIMI, S DAOUDI, I MBARKI, I ADRIF, H ELKACEMI, S ELMAJJAOUI, T KEBDANI, H ERRIHANI, N BENJAAFAR}

\begin{abstract}
Osteoblastoma is a rare benign primary bone tumor. It accounts for $3 \%$ of benign and $1 \%$ of all primary bone tumors. They typically involve the posterior elements, although extension through the pedicles into the vertebral body is not uncommon. These osseous neoplasms usually present in the 2nd decade of life with dull aching pain, which is difficult to localize. The treatment goal is complete surgical resection. This treatment limits the risk of recurrence. Adjuvant radiotherapy and chemotherapy are generally not undertaken, although some have advocated their use after less aggressive surgical maneuvers or with residual tumor.
\end{abstract}

Index Terms - Cervical, benign, bone tumors, Osteoblastoma .

\section{INTRODUCTION}

Osteoblastomas are rare and benign primary bone tumors. They may be locally aggressive and tend to affect the axial skeleton more often than their histologic relative, osteoid osteoma.

Patients typically present around the second to third decades of life. Cervical spine localization represents $9-39 \%$ of all spinal lesions [1].

Osteoblastomas can have a wide range of radiographic patterns. Lesions are typically larger than $2 \mathrm{~cm}$ in size although smaller lesions may occur [2] - [3].

Radical surgical excision is often the treatment of choice. Pre-operative embolization is commonly carried out to reduce bleeding risk although surgery needs to be performed at a very short time interval in order to avoid reconstitution of collateral blood supply. Percutaneous ablation is an emerging modality for treatment of these lesions (as well as osteoid osteoma) [4].

\section{CASE REPORT}

The patient, a 22-year-old man presented with left postero-lateral cervical pain of month duration. Pain was worse during the night and aggravated by neck movements. $\mathrm{He}$ had a spastic torticollis with tilt to the left side. Neurological examination was normal. CT scan showed a central nidus with the tumor encroaching the vertebral artery foramen anteriorly. Cervical MRI showed a process of C7's left pedicle which fills overlying end underlying foramens . It spreads in intracanalary, infiltrates left paravertebral muscle to supraclavicular fossa and in the endothoracic to the pulmonary apex.

TOUIMI Samia Hajar, DEPARTMENT OF RADIOTHERAPY, NATIONAL INSTITUTE OF ONCOLOGY, RABAT, MOROCCO

DAOUDI Sara, DEPARTMENT OF ONCOLOGY, NATIONAL INSTITUTE OF ONCOLOGY, RABAT, MOROCCO

MBARKI Imane, DEPARTMENT OF RADIOTHERAPY, NATIONAL INSTITUTE OF ONCOLOGY, RABAT, MOROCCO
The patient received two incomplete surgical resections at 7 months apart.

He then received 3-D conformational radiotherapy at the total dose of $44 \mathrm{~Gy}$ in 22 fractions of $02 \mathrm{~Gy}$ per fraction on 30days. The patient has been regularly reviewed in follow-up 26 months after the end of treatment and has no symptoms.
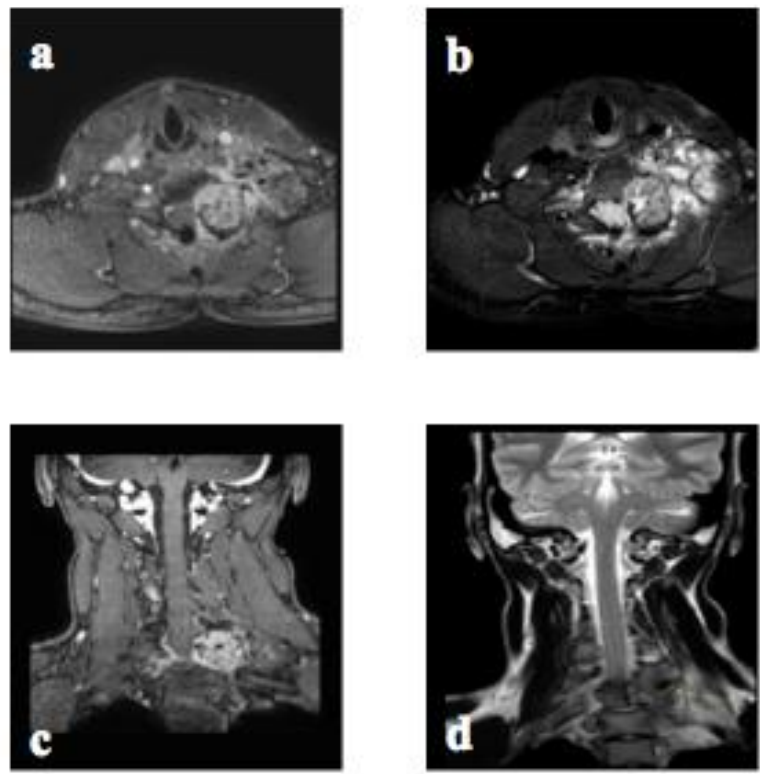

Figure : Cervical MRI showing a process of $\mathrm{C7}$ a/ axial T1 weighted sequence with injection $\mathrm{b} /$ axial $\mathrm{T} 2$ weighted sequence $\mathrm{c} /$ coronal $\mathrm{T} 1$ weighted with injection sequence $\mathrm{d} /$ coronal $\mathrm{T} 2$ weighted sequence

\section{DISCUSSION}

Osteoblastomas are relatively rare benign bone tumors, accounting for about $1 \%$ of all primary bone tumors and $3 \%$ of benign bone tumors [5] . About half of osteoblastomas have a spinal location; $20 \%$ are located in the cervical spine within the spinous and transverse processes, and another $17 \%$ of spinal osteoblastomas are found in the sacrum. Furthermore, it can undergo malignant transformation to osteosarcoma [6] - [7].

In any case, spinal osteoblastomas mostly involve the posterior spinal elements, including pedicles, spinous, and transverse processes and lamina, with the thoracolumbar spine being most frequently affected. [8]

Although it is consider a benign tumor, spinal lesions recurrence is not uncommon and have been reported in 9.7 $-15 \%$ of series of spinal osteoblastomas [7].

Men are more frequently affected than women, with a ratio of $2-3 / 1$, respectively. As such, male patients younger than 30 years are usually affected, with 20 years being the average age at presentation [9] .

Patients with osteoblastoma usually complain about neck 
pain and stiffness. Other common complaints include neurological symptoms, torticollis, and scoliosis. Occasionally, patients with osteoblastoma present with severe neurological deficit due to a large tumor mass invading the spinal cord [10].

The diagnosis is usually made by CT scan [11]. It will delineate the location and osseous involvement of the mass [6]. Imaging with CT scan seems to be superior compared to MRI in terms of the further characterization of the lesion with regard to the presence of a nidus and matrix mineralization. On the other hand, MRI best defines the soft tissue extension and also aids in detection of non-specific reactive marrow and soft tissue edema [12].

A CT scan may reveal calcification and mineralization of the nidus. Another pattern, which is the most commonly seen, involves an expansible lesion with a multitude of small calcifications and a prominently sclerotic rim .

The most aggressive variant displays an expansible pattern, with matrix calcifications, cortical bone destruction, and paravertebral and epidural extension [13]. These more aggressive types of osteoblastomas may radiographically mimic aneurysmal bone cysts, osteosarcomas, or bone metastases [14] - [15].

Osteblastomas display an intermediate to low signal on T1-weighted MRI, whereas T2-weighted MRI depicts an intermediate to high signal [16]. A variable enhancement pattern has been noted on MRI [12]- [17]. The reactive area surrounding the osteoblastoma often enhances on MRI, which may confound the interpreted boundaries of the lesion [13]. A "flare phenomenon» has been described in spinal osteoblastomas.

The aim of surgical treatment is to have a complete excision with free margins, decompression of neural tissue and fixation of the spine when deemed necessary [18].

Surgical excision is the treatment of choice for osteoblastoma.This treatment limits the risk of recurrence.The main reason for high rate of recurrence is incomplete resections [9] - [19]. Total excision of an osteoblastoma has been shown to have a more favorable outcome than subtotal excision (curettage) combined with radiation therapy. It has also been shown that total excision reduces relapse rates [10].

Despite complete surgical excision, recurrence occurs in around $10 \%$ [20].

Radiation therapy for spinal osteoblastomas is a controversial topic among experts.

Radiotherapy is limited to tumors where complete excision is not possible or the tumor continues to grow despite excision. However, malignant transformation after radiation therapy is reported [20]. Radiotherapy and chemotherapy, either together or individually, have been used for patients with unresecable lesions or in cases of recurrent disease [21]. Recurrence-free survival of up to 25 years after adjuvant radiotherapy has been reported in the literature [21] - [22]. The optimal dose for radiation has been reported to be a fractionated dose of 50Gy, giving 2 Gy for 5 days per week, over the course of 5 weeks [22]. Radiation therapy usually causes either arrest of the tumor's growth, or partial reduction in its size. Longitudinally, radiotherapy causes ossification of the tumor. It is rare that radiation can be successfully used as monotherapy.

\section{CONCLUSION}

Persistent neck pain in a young patient can be because of spinal tumors. Proper investigation and surgery can lead to a successful outcome.

\section{ACKNOWLEDGMENT}

We thank Radiotherapy department and our radiotherapist-s colleagues at national institute of oncology of Rabat who provided care and support for the patient.

\section{REFERENCES}

[1]. Trübenbach J, Nägele T, Bauer T et-al. Preoperative embolization of cervical spine osteoblastomas: report of three cases. AJNR Am J Neuroradiol. 2006;27 (9): 1910-2.

[2]. Eisenberg RL. Bubbly lesions of bone. AJR Am J Roentgenol. 2009;193 (2): W79-94.

[3]. Rodriguez DP, Poussaint TY. Imaging of back pain in children. AJNR Am J Neuroradiol. 2010;31 (5): 787-802.

[4]. Atesok KI, Alman BA, Schemitsch EH et-al. Osteoid osteoma and osteoblastoma. J Am Acad Orthop Surg. 2012;19 (11): 678-89.

[5]. Saccomanni B. Osteoid osteoma and osteoblastoma of the spine: a review of the literature. Curr Rev Musculoskelet Med 2009;2:65-7.

[6]. Samdani A,Torre-Healy A,Chou D, Cahill AM, Storm PB .Treatment of osteoblastoma at C7 : a multidisciplinary approach. A case repord and review of the literature. Eur SpineJ.2009;18Supp12:196-200

[7]. Yilmaz C, Civelek E, Caner H, Aydin E, Gerilmez A, Altinors N.Osteoblastoma of $\mathrm{C} 2$ corpus: 4years follow-up.Asian SpineJ. $2012 ; 6(2): 136-9$

[8]. Kan P, Schmidt MH. Osteoid osteoma and osteoblastoma of the spine. Neurosurg Clin N Am 2008;19:65-70

[9]. Andreas A. Argyriou, Vasileios Panagiotopoulos, Aristeidis Masmanidis, Fotios Tzortzidis, and Dimitrios Konstantinou, Destructive cervical spine osteoblastoma at C5 in a young patient initially presenting with quadriparesis : case report and revie of the literature. The Journal of Emergency Medicine, Vol. 44, No. 1, pp. e1-e4, 2013

[10]. Yin H, Zhou W, Yu H, Li B, Zhang D, Wu Z, et al. Clinicalcharacteristics and treatment options for two types ofosteoblastoma in the mobile spine : a retrospective study of 32 cases and outcomes. Eur Spine J. 2014 ; 23(2) :411-6

[11]. Hadgaonkar SR,Shyam AK,Shah KC, Khurjekar KS, Sancheti PK. Extraosseous thoracic foraminal osteoblastoma : diagnostic dilemma and management with 3year follow-up.Asian spine J.2014;8 (5) : 689-94

[12]. Shaikh MI, Saifuddin A, Pringle J, Natali C, Sherazi Z. Spinal osteoblastoma: CT and MR imaging with pathological correlation. Skeletal Radiol 1999;28:33-40.

[13]. Boriani S, Weinstein JN: Oncologic Classification of Vertebral Neoplasms. New York: Thieme, 2006

[14]. Orguc S, Arkun R: Primary tumors of the spine. Semin Musculoskelet Radiol 18:280-299, 2014

[15]. Wan Y, Zhao W, Jiang Y, Liu D, Meng G, Cai Y: b-catenin is a valuable marker for differential diagnosis of osteoblastoma and osteosarcoma. Hum Pathol 45:1459-1465, 2014

[16]. Pobiel R, Pitt A: Radiologic Imaging of Tumors of the Spine, Spinal Cord, and Peripheral Nerves. New York: Thieme, 2006

[17]. Jacobs WB, Fehlings MG: Primary Vertebral Column Tumors. New York: Thieme, 2006

[18]. Gopal Sedain, ,Ram K Shrestha, , Mohan R Sharma, Cervical Osteoblastoma: A Rare Primary Spinal Tumor. Nepal Journal of Neuroscience 13:51-53, 2016

[19]. Weatherley CR, Jaffray D, O'Brien JP.Radical excision of an osteoblastoma of the cervical spine.A combined anterior and posterior approach .J Bone Joint Surg Br.1986 : 68 (2) :325-8

[20]. Denaro V, Denaro L, Papalia R, Marinozzi A, Di Martino A.Surgical management of cervical spine osteoblastomas. Clin Orthop Relat Res $455: 190-195,2007$ 
[21]. Galgano M A, Goulart C R, Iwenofu H, Chin L S, Lavelle W and Mendel E, Osteoblastomas of the spine: a comprehensive review; Neurosurg Focus 41 (2):E4, 2016

[22]. Singh DK, Das KK, Mehrotra A, Srivastava AK, Jaiswal AK, Gupta P, et al: Aggressive osteoblastoma involving the craniovertebral junction: A case report and review of literature.J Craniovertebr Junction Spine 4:69-72, 2013

[23]. Weber MA, Sprengel SD, Omlor GW, Lehner B, Wiedenhöfer B, Kauczor HU, et al: Clinical long-term outcome, technical success, and cost analysis of radiofrequency ablation for the treatment of osteoblastomas and spinal osteoid osteomas in comparison to open surgical resection.Skeletal Radiol 44:981-993, 2015 